\title{
HOLOCENE PALEONTOLOGY OF BAT CAVE, EDMONSON COUNTY, KENTUCKY
}

\author{
Mona Colburn ${ }^{*}$, Rickard Toomey III², Chris Widga ${ }^{1}$, And Rick Olson²
}

\begin{abstract}
We report the excavation and analysis of a Chiroptera-dominated bonebed from Bat Cave, Edmonson County, Kentucky. Paleontological materials recovered in 1999 offered new insight into formation processes of the bonebed. Stratigraphic and geochronological information indicate a long, episodic history of the deposit spanning much of the Holocene. The vertebrate assemblage is dominated by Myotis spp. Although initially believed to represent a single, catastrophic kill event due to historic flooding, our results suggest that the Bat Cave bonebed was formed by a minimum of eleven accumulation events that took place between approximately 2200 and 10,800 cal BP.
\end{abstract}

\section{INTRODUCTION}

Before Mammoth Cave was officially designated as a national park in 1936, three groups, the Mammoth Cave National Park Association, Kentucky National Park Commission, and the National Park Service (NPS), jointly operated the Mammoth Cave property; in 1941 the NPS became fully responsible (Goode, 1986). Bat Cave, presumably named for its large bat population, is located within the park in the limestone bluff above the Green River (Fig. 1). Since at least the 1930s, Bat Cave has drawn official attention, where an extensive deposit of bat bones has been of particular interest (Bailey, 1933; Hibbard, 1935a; Jegla, 1961; Keefer, 1969; MacGregor, 1991; Trevor-Deutsch, 1972).

In the 1930s, Claude Hibbard was concerned about management practices that were driving bats out of the park's caves. In July of 1934, Hibbard made a special trip to Bat Cave to assess the bat situation. He noted the virtual absence of bats, which he thought was due to local residents making fires at the base of formations, blasting them with dynamite in order to break off cave onyx for tourist items, or the Kentucky Park Commission's program to blast shut more than 25 cave entrances, including Bat Cave (Hibbard, 1935a). Hibbard did not mention that the absence of a large number of bats might have been due to the timing of his visit in July, a month when most species would be living outside the cave. Hibbard noted during his July 1934 trip that each of the two passages in Bat Cave "had been blasted shut but later worked out so that one could worm their way over the blasted material just below the ceiling though not enough room to allow a lantern to remain upright" (Hibbard, 1935a, p. 2). On June 19, 1935, Hibbard made another special trip to Bat Cave with geologist E. R. Pohl, about which he wrote,

the left avenue into the main portion of the cave had broken down due to the blast either early this spring or last winter. It is in this avenue that the bats hibernate. The question as to whether the bats were trapped by this breakdown cannot be answered until it is removed. The breakdown is small though forming a tight plug since the opening was just large enough to allow a medium sized man to slide through into the avenue. This should be opened by all means. (Hibbard, 1935a, p. 2)
In his diary entry for June 19, 1935, Hibbard (1935b) wrote, "Bat Cave was found closed at the main passage (I was through this passage a year ago)." Again, Hibbard's primary recommendation was "That all caves now closed due to blasting in the Park Area on our land shall be opened" (Hibbard, 1935a, p. 3). A report by E. R. Pohl (1935) dated July 1935 noted that an emergency request had been made to open Bat Cave, which had been closed "several years ago by the Kentucky National Park Commission." Documentary sources do not indicate whether this request was acted upon.

In 1960, Thomas Jegla became the first researcher to report the bone deposit in the A-Survey of Bat Cave. He described the deposit as measuring about 10-m long by $1.2-\mathrm{m}$ wide by $0.6-\mathrm{m}$ deep, with bones concentrated in the upper $8 \mathrm{~cm}$ (Jegla, 1961). Jegla collected a $45-\mathrm{cm}^{3}$ sample (exact dimensions unknown) from which he counted humeri and measured ten bat skulls. Based on these measurements, Jegla's study concluded that the skulls were consistent with those of Myotis sodalis and that the deposit was an accumulation of drowned bats.

In the mid-1990s Mammoth Cave Park Ecologist Rick Olson and Illinois State Museum researcher Rick Toomey proposed another examination of the bonebed as part of the Mammoth Cave Paleontological Inventory Project (Colburn, 2005). On May 20, 1999, Illinois State Museum researchers Toomey and Mona Colburn, accompanied by Olson, visited Bat Cave to excavate a small section of bones from the wall of the crawlway. It is unclear how effectively Hibbard's (1935a) number-one recommendation, opening the dynamited caves, was implemented at Bat Cave. We observed an 11-m long crawlway that had been dug through sediments in the passage of the A-Survey; it does not seem to be much larger than that described by Hibbard nearly 80 years ago (Fig. 2). Because the crawlway was dug through sediments containing a large,

\footnotetext{
* Corresponding author: colburn@museum.state.il.us

${ }^{1}$ Illinois State Museum, Research and Collections Center, 1011 E. Ash St., Springfield IL62703 colburn@museum.state.il.us

${ }^{2}$ Mammoth Cave National Park, International Center for Science and Learning. Mammoth Cave N.P., PO Box 7, Mammoth Cave, KY 42259
} 


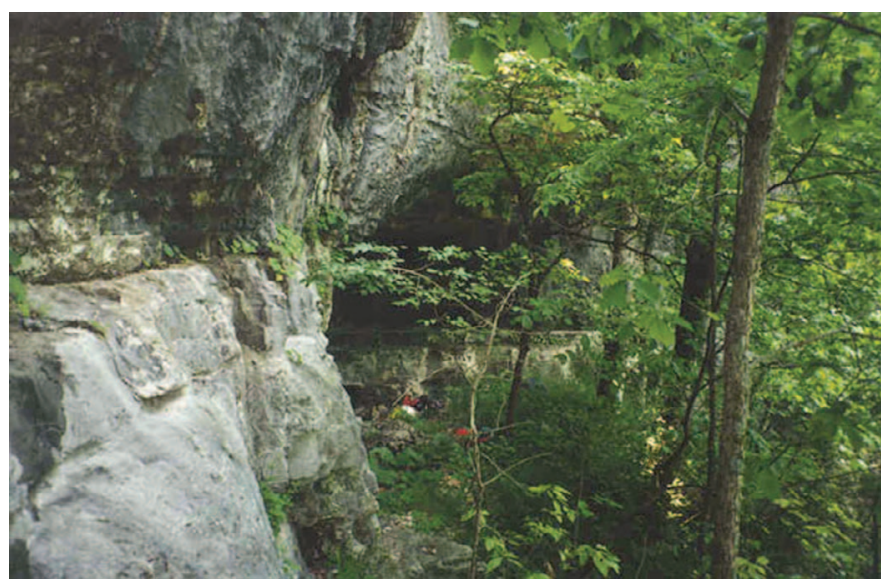

Figure 1. Approach and entrance to Bat Cave.

concentrated accumulation of bat bones, it provides an excellent profile of the bonebed (Fig. 3).

This study reports the results of paleontological work in Bat Cave, in particular the recent establishment of a geochronological framework for bonebed formation and the identification of bat taxa. Although the mechanism is still unclear, we also explore possible scenarios of bone accumulation.

\section{Methods}

The entrance to Bat Cave lies $28 \mathrm{~m}$ above the normal pool of the Green River as ponded by Lock and Dam No. 6 (Fig. 4). Survey Station A9 has an elevation of 137.9 mamsl, $9.7 \mathrm{~m}$ above the modern river level. This station (Figs. 4 and 5), which is located on the ceiling of the passage, served as an excavation datum. The surface of the

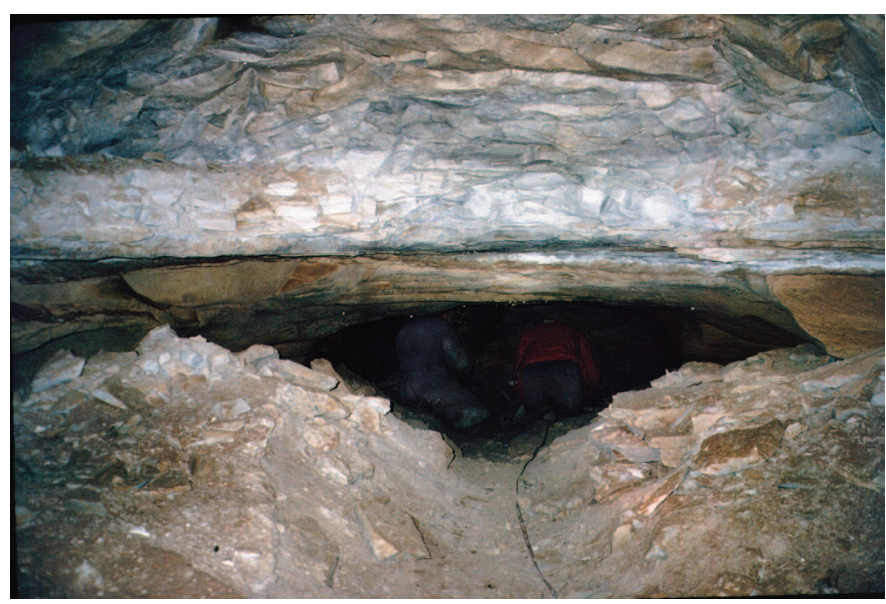

Figure 2. The excavated crawlway that cuts through the bone deposit in Bat Cave, looking north. The passage is approximately 1-m high.

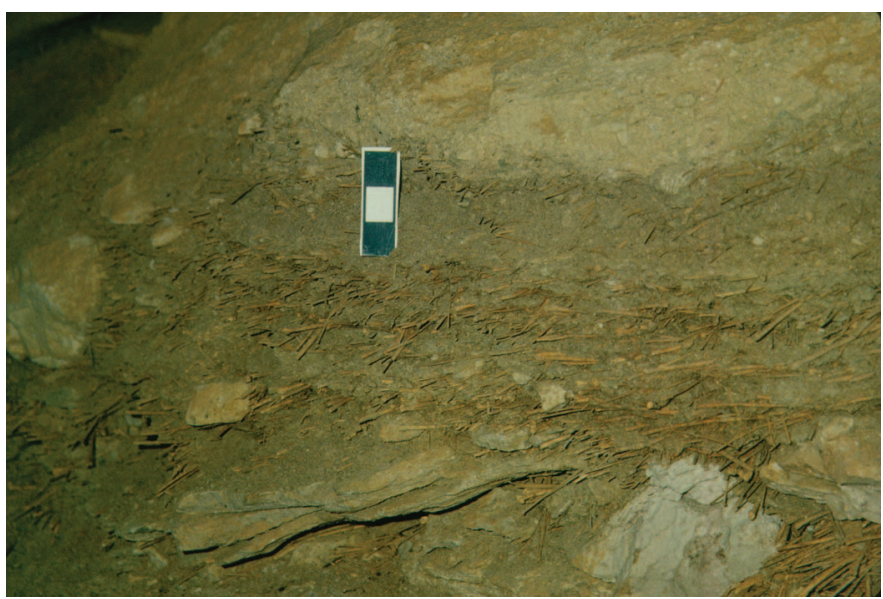

Figure 3. Massive deposit of bat bone exposed in the wall of the crawlway in the Bat Cave. Scale bar in $\mathrm{cm}$.

excavation area was $50-\mathrm{cm}$ below this datum, along the left edge of the crawl. A single unit (Unit 1) measuring $15-\mathrm{cm}$ along the trail by $10-\mathrm{cm}$ wide and $40-\mathrm{cm}$ high was excavated in eleven levels, which ranged from $2.0-\mathrm{cm}$ to $7.0-\mathrm{cm}$ thick (Table 1). The deposit appears to have zones of almost sterile sediment separating some of the bones. These levels had to be teased out during excavation because of the intertwined nature of the bone deposits, thus the excavated levels reflect natural stratigraphy. After excavation, the small pit was lined with plastic and backfilled with rocks and sediment.

All samples were taken to the Illinois State Museum Research and Collection Center and dry-sifted through small mesh geological screens. Figure 6 shows an example of bone-deposit material from Level 4 that was $>2.36 \mathrm{~mm}$; larger rocks have been removed from this sample. Screened material from Level 4 contains a large ratio of bone to rock. Bones selected for analysis included cranial elements and long bones that could be measured or could provide information for identification. To be consistent with Jegla's use of bat humeri to obtain an estimated number of individuals, distal humeri were also counted in the 1999 sample. All specimens selected for study were identified and measured by Blaine W. Schubert and one of us (Colburn) in 1999; Schubert screened and sorted samples and measured post-cranial elements of bat, and Colburn measured bat dentaries and skulls and identified non-bat mammals. Standard measurements on limb and skull elements follow Toomey (1993). The Illinois State Museum comparative osteology collections were referred to for making identifications.

Six Myotis species are known to live in the eastern US (Harvey et al., 2011).The size range for each taxon was assessed using the Museum's comparative samples and published size ranges for Myotis (e.g., Miller and Allen, 1928; van Zyll de Jong, 1984). Despite excellent comparative 


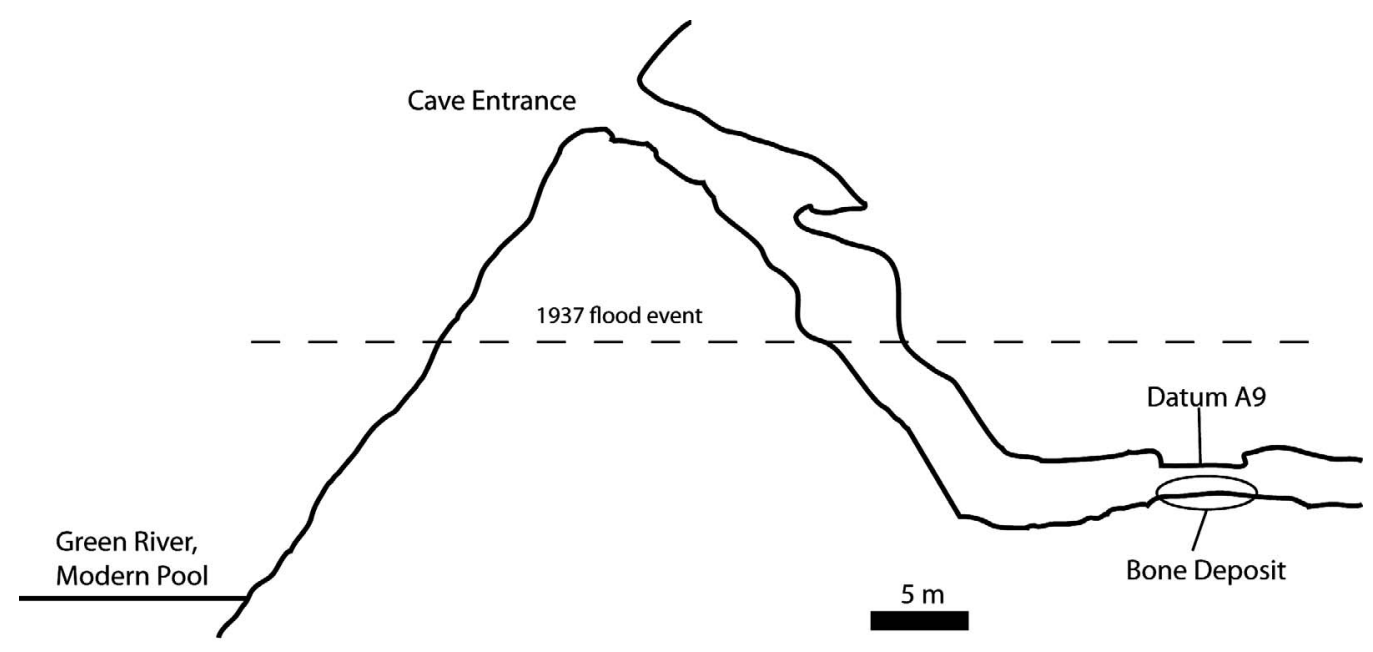

Figure 4. Vertical section showing the elevation of the bonebed relative to the Green River and the cave entrance. Dashed line indicates the height of a 1937 flood event. Figure based on Jegla (1961).

specimens and references to body size, it is still difficult to distinguish between different species of Myotis on the basis of fragmentary or undiagnostic fossil material (Czaplewski et al., 2002; Jansky, 2013). In many cases, identification of the Bat Cave Myotis sample is limited to general size class (small, medium, or large Myotis) or only to genus level.

The skull is the most diagnostic element for identifying bat taxa. Dentaries, teeth, humeri, and element size are also useful for identifying bat genera and, potentially, species. In the case of bat dentaries and crania, the most useful characters include shape, overall size, skull measurements, tooth counts, and the presence or absence of a sagittal crest. Measurements were made to the nearest $0.1 \mathrm{~mm}$ using non-metallic $150 \mathrm{~mm}$ dial calipers. The following measurements were taken on bat skulls: greatest length of skull (GLS), condylobasal length (CBL), distance from front of maxilla (excluding incisor) to M3 (I-M3), maxillary breadth at the M3s (M3M3), least interorbital breadth (IOB), maximum breadth of the braincase (BB), occipital depth (OD), and total dentary length (TL). To distinguish Myotis species based on skulls, we relied on GLS, IOB, BB, cranial shape, and presence or absence of a sagittal crest.

The eastern small-footed Myotis (Myotis leibii) is a small-sized bat, whereas the Indiana bat ( $M$. sodalis), the little brown bat ( $M$. lucifugus), the northern long-eared bat (M. septentrionalis), and the southeastern Myotis ( $M$. austroriparius) are medium-sized Myotis, and the gray bat (M. grisescens) is large-sized. Compared to M. lucifugus, $M$. sodalis crania exhibit a pronounced sagittal crest and slightly narrower BB (M. sodalis: 6.4-7.2 mm; M. lucifugus: 7.0-7.6 mm) and IOB (M. sodalis: 3.3-4.3 mm; $M$. lucifugus: $3.6-4.4 \mathrm{~mm}$ ) (Thomson 1982, p. 1). M. leibii dentaries average less than $10-\mathrm{mm}$ in total length (TL) and are more gracile than those of other Myotis.
The majority of unassociated dentaries with 3-1-3-3 tooth counts were identified as Myotis. Because this dentition also occurs in Corynorhinus and Lasionycteris, there is a possibility that some of the dentaries identified as Myotis could represent one of those genera. However, only a single Corynorhinus cranium was identified, and no diagnostic elements of Lasionycteris are present, so it is unlikely that these taxa make up a significant percentage of the assemblage.

Since its discovery, there has been uncertainty surrounding the chronology of the Bat Cave bonebed. Initially, Jegla (1961) suggested the bone accumulation took place in the recent, historic past, possibly during a 1937 flood event. In later correspondence, he allowed the possibility that the accumulation event could have predated European settlement. With these chronological questions in mind, we selected bat bones for ${ }^{14} \mathrm{C}$ dating. Bat radii (Myotis spp.) were selected from excavation levels 2, 6, and 11 in order to assess the chronostratigraphy of the bonebed. Samples were submitted to Nancy Beavan, Rafter Radiocarbon lab, New Zealand, where collagen was isolated through standard acid-base-acid pretreatment. The carbon:nitrogen $(\mathrm{C}: \mathrm{N})$ ratio indicated preservation within the range of modern bone, and qualitative measures of collagen preservation were favorable. Radiocarbon results were calibrated in Calib $7.0 \mathrm{html}$ using the Intcal13 dataset. Two-sigma errors (95\% probability) are reported.

\section{RESULTS}

Within the $6,000 \mathrm{~cm}^{3}$ of excavated material, a total of 3064 bat bones were diagnostic to family or better. The assemblage included five species of bat, four non-bat mammals, one salamander, and one fish (Table 2). Major bone-bearing units were levels 2 through 7, (53 through $73 \mathrm{~cm}$ below datum). To be consistent with Jegla, the 


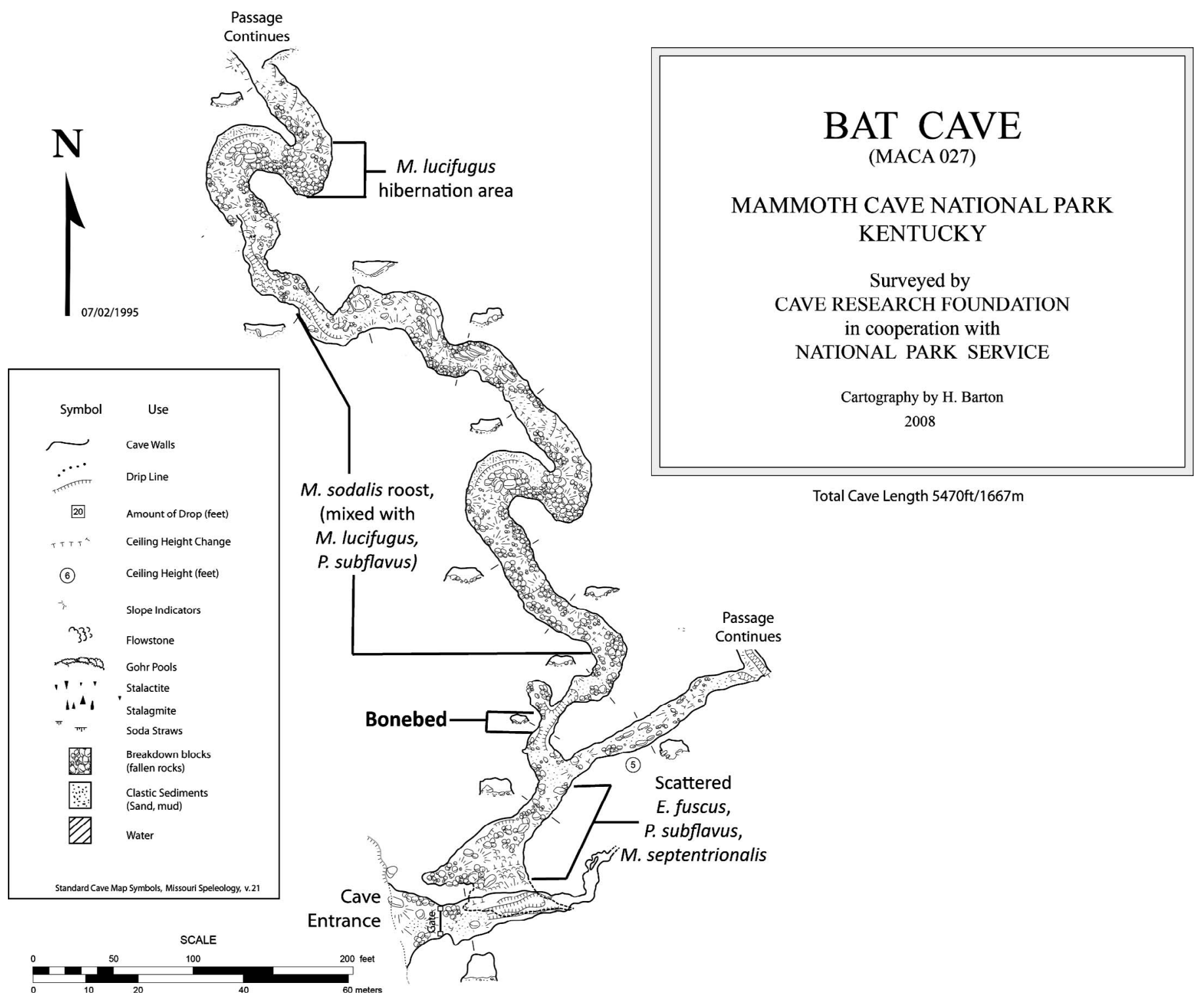

Figure 5. Partial plan map of Bat Cave, Kentucky, showing the area of the bone deposit and the modern bat usage areas. Based on a map courtesy of the Cave Research Foundation.

current study estimated the number of individual bats by counting distal humeri. Clearly, each specimen could not be identified to genus or species. Rather, the size and configuration of most humeri indicate medium-size Myotis; no humeri of large-size bat species were found. Several small humeri could be either tri-colored bat or very small Myotis, although no skull or dentary of a tri-colored bat was identified in the screened osteological material from the deposit. Thus, based on a tally of distal humeri (mostly Myotis spp.), an estimated 1322 individual bats are represented (Table 2).

A total of 141 skull fragments were identified to genus or better based on diagnostic portions (e.g., dentary, maxillary, rostrum). The majority of these specimens are lower jaws of Myotis spp., most being
Table 1. Unit 1 excavation levels.

\begin{tabular}{ccc}
\hline Level & Elevation, cm (Below datum) & Thickness, cm \\
\hline 1 & $50-53$ & 3 \\
2 & $53-55.5$ & 2.5 \\
3 & $55.5-58.5$ & 3 \\
4 & $58.5-61$ & 2.5 \\
5 & $61-66$ & 5 \\
6 & $66-70$ & 4 \\
7 & $70-73$ & 3 \\
8 & $73-75$ & 2 \\
9 & $75-79$ & 4 \\
10 & $79-86$ & 7 \\
11 & $86-90$ & 4 \\
\hline
\end{tabular}


M. Colburn, R. Toomey, C. Widga, and R. Olson

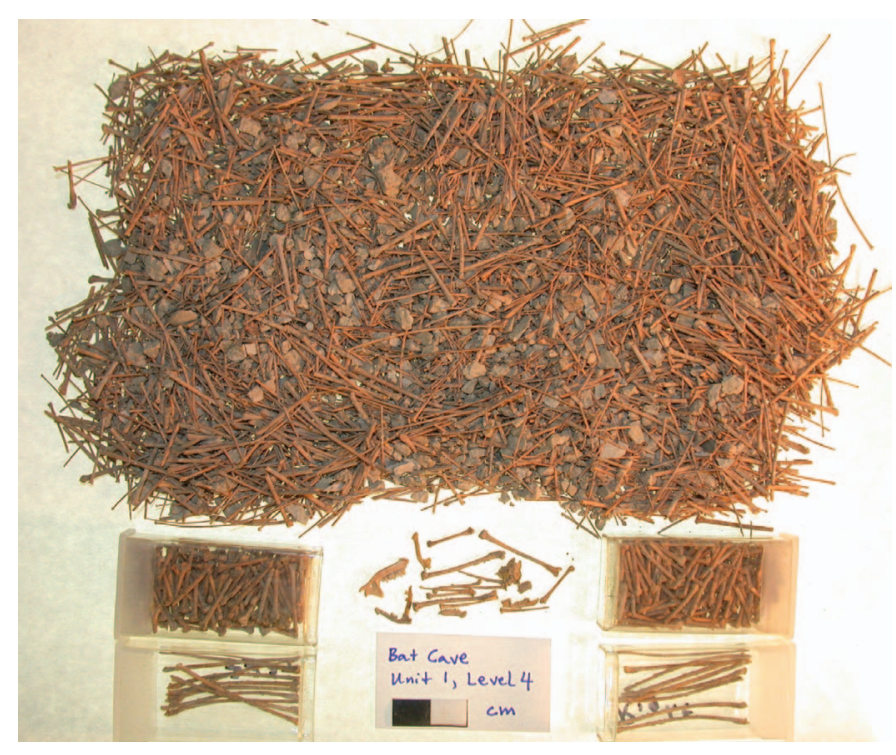

Figure 6. Material from Level $4>2.36 \mathbf{m m}$, with rocks $>12.5 \mathrm{~mm}$ removed before the photo was taken.

from individuals in the medium-size range. Six small dentaries were attributed to $M$. leibii due to their small size $(\mathrm{TL}<10 \mathrm{~mm}$ ) and relatively gracile structure, but no cranial fragments of this species were encountered (Supplementary Table S1).

Two crania of $M$. lucifugus or $M$. cf. lucifugus were identified from Levels 5 and 6 and four crania of $M$. sodalis or M. cf. sodalis from Level 6. A Corynorhinus sp. skull was found in level 5. Eptesicus fuscus was identified from dentaries in Levels 4 and 9 and a canine in Level 10.

Collagen extracted for radiocarbon dating was wellpreserved, and $\delta^{13} \mathrm{C}$ values were within the expected range of modern bats in the area (Table 3). These results indicate that the Bat Cave bonebed spans much of the Holocene (Table 3). A date of $2250 \pm 25$ BP (NZA32583; 2160-2340 cal BP) was reported for Level 2. Bat bones from Level 6 were dated at $3680 \pm 25 \mathrm{BP}$ (NZA32584; 3930-4090 cal $\mathrm{BP})$. At the base of the unit, a date of $9510 \pm 40 \mathrm{BP}$ (NZA32585; 10,610-10,880 cal BP) was acquired from Level 11. The upper half of the assemblage is late Holocene in age. The lower half of the assemblage is early and, possibly, middle Holocene in age.

In addition, the bonebed contained 11 specimens of non-chiropteran animals: two raccoon (Procyon lotor), one deer (Odocoileus virginianus), one mouse-sized rodent, one rat-sized rodent, two plethodontid salamander, two indeterminate mammal, one indeterminate fish, and a fragment that could not be identified beyond bird or mammal. The teeth of a juvenile raccoon (left p4, right dp3) and the unfused metacarpal diaphysis of a fetal deer offer seasonality information for Level 9.

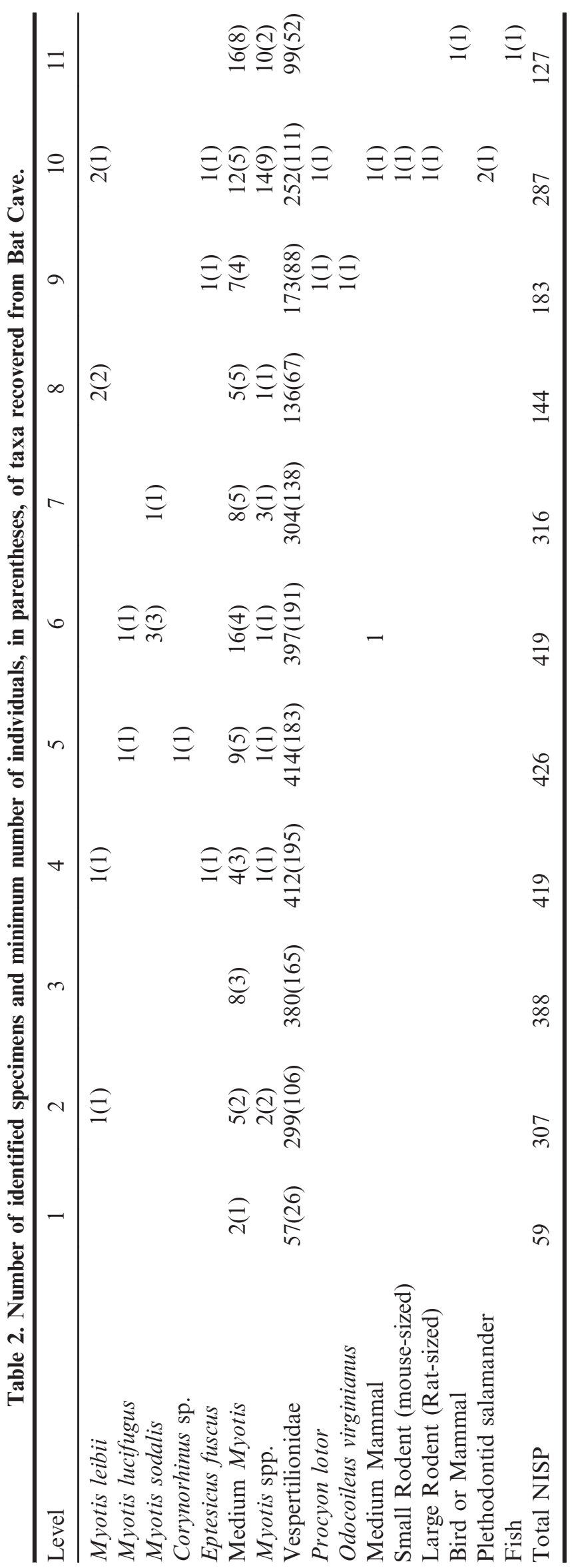

Journal of Cave and Karst Studies, August 2015•95 


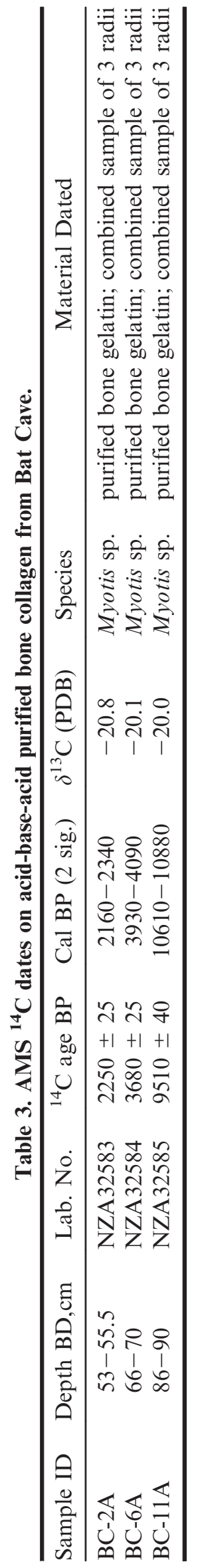

\section{DisCUSSION}

Based on comparisons of the Bat Cave bat specimens with cranial and jaw elements of modern Myotis spp. from the Kentucky area, Jegla (1961) concluded that measurements on fossil crania were consistent with those of Myotis sodalis. MacGregor (1991) identified crania of Eptesicus fuscus, Perimyotis (=Pipistrellus) subflavus, and Myotis spp. from the deposit. The 1999 Illinois State Museum sample contained not only M. sodalis and Eptesicus fuscus, but also $M$. leibii, $M$. cf. lucifugus, hundreds of bones of indeterminate medium-sized Myotis spp., and Corynorhinus sp.

Consideration of the ${ }^{14} \mathrm{C}$ chronology based on directdated bat remains clearly indicates that the Bat Cave bonebed predates historic flooding of the Green River and anthropogenic modification of the modern entrance by blasting. However, causes of death and the mechanisms of accumulation are still unclear. The high density of bat remains within the passage suggest either a series of catastrophic death events or the occasional concentration of bones from attritional deaths over time. The bonebed passage is not an ideal location for a large bat roost. The modern passage contains no concentrations of roosting bats, although there are hibernacula deeper within the cave (Fig. 5). Disease or flooding are possible causes of death in the Bat Cave fauna. Both may have occurred periodically through the Holocene.

The concentration of disarticulated bones within the bonebed passage suggests a mechanism of post-mortem accumulation is at work. Two taphonomic scenarios could be invoked to explain this concentration. The first scenario is periodic flooding within the cave due to an elevated water table that could have had the effect of redistributing and concentrating the remains of fauna that died upstream in the passage. The cave entrance is at a much higher elevation than the A9 section where the bonebed is located, and would have provided a barrier to high water, causing ponding and reduced flow in the area of the bonebed during draining of the cave. Alternatively, high floods from the Green River could have submerged the entrance, causing high-water conditions far back into the cave. As the floodwaters receded, ponding in low areas like the A9 section could have concentrated the bones of animals from nearby passages. These scenarios are not mutually exclusive.

Some non-bat remains within the bonebed offer clues to seasonality. A fetal deer metacarpal, identified on the basis of its small size, was recovered from Level 9 and suggests a winter death. This estimate is based on the rut taking place in November-December and parturition in May (Barbour and Davis, 1974, p. 287). Although young deer bones may be consumed or transported by carnivores or rodents, no gnawing is present on the surface of this specimen, so transport by woodrats or carnivores is unlikely. The presence of juvenile raccoon premolars may 
support late winter to late spring as well. In Kentucky, raccoons mate from January to March and births can occur from early March through May (Barbour and Davis, 1974 , p. 256). Because the bonebed is probably a secondary deposit, these seasonality indicators do not reflect the season-of-death for the bat fauna. Rather, they simply indicate that Bat Cave was open and accessible during the winter.

Jegla estimated that the Bat Cave deposit represented some 300,000 individual bats; the current study did not attempt to make an estimate for the entire bonebed. On his January 1960 trip, Jegla saw hibernating Myotis sodalis and recorded a temperature of $4{ }^{\circ} \mathrm{C}$ in the passage just beyond the bonebed. Researchers before and after Jegla have reported on the various species found in Bat Cave. The United States National Museum has Perimyotis subflavus and M. lucifugus specimens collected by Vernon Bailey in 1929 from Bat Cave (Smithsonian Institution, 1996), where he wrote that the latter species was found in "small numbers... in late September" (Bailey, 1933, p. 453). In addition, Bailey commented that Bat Cave contains "large numbers" of M. sodalis (Bailey 1933, p. 457). In 1959 Hall captured M. austroriparius and M. sodalis (Smithsonian Institution, 1996). In the fall of 1969, Scott Keefer, a zoology student at Southern Illinois University, estimated that Bat Cave housed 200 to 250 M. sodalis and 300 M. lucifugus; in February of 1971 he estimated counts to be 200 to 300 and 250 to 300 for the two species and noted that $M$. lucifugus had shifted its hibernation location (Keefer, 1971). In November of 1972, B. Trevor-Deutsch of Carleton University, Ottawa, Canada, observed approximately 300 hibernating bats, primarily Myotis, in the first 1000 feet $(\sim 300 \mathrm{~m})$ of the "large tubular part of this cave" and noted the bone deposit in the crawlway that led to the tubular passage (Trevor-Deutsch, 1972).

Endangered bat species in Kentucky are monitored by the Kentucky Department of Fish and Wildlife Resources, the Kentucky State Nature Preserves Commission, the U.S. Forest Service, and the U.S. Fish and Wildlife Service. A variety of bats have been recorded in Bat Cave since regular surveys were initiated by these agencies. Recent trips documented a hibernation roost of Myotis sodalis and a $M$. lucifugus hibernaculum in the passage beyond the bonebed (Fig. 5). Deeper in the cave, scattered M. lucifugus and Perimyotis subflavus occur, and a summer roost of M. grisescens has been recorded.

Bat counts are conducted every other winter. From 1985 to 1994, estimates of hibernating M. lucifugus remained consistent, in the range of 223 to 311 . In recent years their numbers have been more varied, occasionally dropping below 100 individuals. M. sodalis declined from a high of 212 in 1982 to the current low, fewer than 50 individuals; $M$. lucifugus was not counted that year. In addition, small numbers of hibernating $P$. subflavus, Eptesicus fuscus, Corynorhinus rafinesquii, $M$. septentrionalis, and M. grisescens have been observed over the years, and a bachelor colony of $M$. grisescens is present in summer (data on file, Mammoth Cave National Park). Because it is likely that taphonomic mechanisms have concentrated remains from periods of unknown duration, it is difficult to compare modern bat counts to estimates of individuals contained within the bonebed. Species composition of the identifiable cranial material found in the present study of the bonebed (though limited in numbers) suggests that the contributing population was a mixture of medium-sized Myotis (M. lucifugus, M. sodalis), M. leibii, E. fuscus, and Corynorhinus sp.

\section{Conclusions}

Paleontological investigations of the Bat Cave bone deposit suggest multiple events that concentrated bat remains into a series of relatively discrete bonebeds over the last 10,800 years. Although sedimentation rates and accumulation frequencies were not uniform throughout this period, the earliest event at the base of the section occurred around 10,800 cal BP, while the most recent event occurred around $2200 \mathrm{cal}$ BP. All bonebeds within the section are dominated by Chiroptera, especially Myotis spp. It is difficult to compare the paleoecological record of chiropteran osteological materials in Bat Cave to the modern record of population counts due to difficulty in identifying different species within the genus Myotis and uncertainty in the mode of accumulation. However, a number of taxa are identified based on diagnostic crania, including M. lucifugus, M. sodalis, M. leibii, Eptesicus fuscus, and Corynorhinus sp.

Supplemental Information, Table S1. Bat skull elements and measurements from Bat Cave, Unit 1. Abbreviations: n/m-not measured, med.=medium-sized, $\mathrm{L}=$ left; $\mathrm{R}=$ right; crest $=$ sagittal crest. Greatest length of skull (GLS), condylobasal length (CBL), distance from front of maxilla (excluding incisor) to M3 (I-M3), maxillary breadth at the M3s (M3M3), least interorbital breadth (IOB), maximum breadth of the braincase (BB), occipital depth (OD), and total dentary length (TL).

\section{ACKNOWLEDGEMENTS}

This study benefited from the insight and assistance of Blaine Schubert (East Tennessee State University) and three anonymous reviewers. Funding for fieldwork and analysis was provided by the National Park Service (cooperative agreement 1443 CA5530 97 003). Funding for radiocarbon dating was provided by the Illinois State Museum Society.

\section{REFERENCES}

Bailey, V., with chapters by Bailey, F.M., and Giovannoli, L., 1933, Cave life of Kentucky, The American Midland Naturalist, v. 14, no. 5, 385-635.

Journal of Cave and Karst Studies, August 2015•97 
Barbour, R.W., and Davis, W.H., 1974, Mammals of Kentucky, Lexington, University Press of Kentucky, 368 p.

Colburn, M., 2005, Paleontological Inventory Project, Vertebrate Remains found in select passages and caves at Mammoth Cave National Park, Kentucky. Illinois State Museum Landscape History Program, Technical Report, no. 2005-1199-007.

Czaplewski, N.J., Puckette, W.L., and Russell, C., 2002, A Pleistocene tapir and associated mammals from the southwestern Ozark Highland, Journal of Cave and Karst Studies, v. 64, no. 2, 97-107.

Goode, C.E., 1986, second edition 1997, World Wonder Saved: How Mammoth Cave Became a National Park, Mammoth Cave, Mammoth Cave National Park Association, 92 p.

Harvey, M.J., Altenbach, J.S., and Best, T.L., 2011, Bats of the United States and Canada, Baltimore, John Hopkins University Press, 224 p.

Hibbard, C.W., 1935a, Special report on the bat situation at Mammoth Cave National Park with recommendations, Unpublished report on file at Mammoth Cave National Park, dated July 22, 1935, 3 p.

Hibbard, C.W., 1935b, Diary entries for June 1, 1934-August 22, 1935, Unpublished, on file at Mammoth Cave National Park.

Jansky, K.J., 2013, Identifying Myotis species using geometric morphometrics and its implications for the fossil record and conservation [MS thesis], Johnson City, East Tennessee State University, Electronic Theses and Dissertations Paper 1145, $87 \mathrm{p}$.

Jegla, T.C., 1961, A study on deposits of bat bones in Mammoth Cave National Park, Unpublished manuscript on file at Mammoth Cave National Park, $26 \mathrm{p}$.

Keefer, S.D., 1969, Letter report written to Edwin Rothfuss, Chief IRM, dated December 3, 1969, regarding estimates of bats in Mammoth Cave National Park, Unpublished, on file at Mammoth Cave National Park.

Keefer, S.D., 1971, Observations on bat colonies in Mammoth Cave National Park 13, 14, 15 February 1971: Unpublished report and letter dated April 28, 1971, to Edwin L. Rothfuss, Chief of IRM, Mammoth Cave National Park, On file at Mammoth Cave National Park.

MacGregor, J.,1991, Responses of winter populations of the federally endangered Indiana Bat (Myotis sodalis) to cave gating in Kentucky, in Foster, D.L., Foster, D.G., Snow, M.M., and Snow, R.K., eds., National Cave Management Symposium Proceedings, Bowling Green, Kentucky, October 23-26, 1991, Horse Cave, Kentucky, American Cave Conservation Association, p. 364-370.

Miller, G.S., and Allen, G.M., 1928, The American Bats of the Genera Myotis and Pizonyx: Washington, D.C., Bulletin of the United States National Museum 144, 218 p. doi, 10.5479/si.03629236.144.i.

Pohl, E.R., 1935, Weekly activity report of Dr. E. R. Pohl, Geologist, Mammoth Cave National Park Project for period of July 22 to 27, 1935, Unpublished report on file at Mammoth Cave National Park, $2 \mathrm{p}$.

Smithsonian Institution, 1996, Unpublished list of bats from Kentucky curated at the United States National Museum, printed out by Craig Ludwig, Scientific Data Manager, Divisions of Mammals and Birds.

Toomey, III., R.S., 1993, Late Pleistocene and Holocene faunal and environmental changes at Hall's Cave, Kerr County, Texas [Ph.D. dissertation], Austin, University of Texas, 560 p.

Thomson, C.E., 1982, Myotis sodalis. Mammalian Species, no. 163, p. $1-5$.

Trevor-Deutsch, B., 1972, Observations made at several caves in Mammoth Cave National Park, Kentucky, Unpublished report on file at Mammoth Cave National Park, 3 p.

van Zyll de Jong, C.G., 1984, Taxonomic relationships of Nearctic smallfooted bats of the Myotis leibii group (Chiroptera: Vespertilionidae): Canadian Journal of Zoology, v. 62, no. 12, p. 2519-2526. doi: 10.1139/z84-369. 
Supplemental Material

M. Colburn, R. Toomey, C. Widga, and R. Olson - Holocene palentology of Bat Cave, Edmonson County, Kentucky. Journal of Cave and Karst Studies, v.77, no.2, p.91-98.

Table S1. Bat skull elements and measurements from Bat Cave, Unit 1. Abbreviations: $\mathbf{n} / \mathbf{m}$-not measured, med.=medium-sized, $L=$ left; $R=$ right; crest=sagittal crest. Greatest length of skull (GLS), condylobasal length (CBL), distance from front of maxilla (excluding incisor) to M3 (I-M3), maxillary breadth at the M3s (M3M3), least interorbital breadth (IOB), maximum breadth of the braincase (BB), occipital depth (OD), and total dentary length (TL).

\begin{tabular}{|c|c|c|c|c|c|c|c|c|c|c|c|}
\hline & & Skull element & & & & & & & & & \\
\hline Level & Taxon & & TL & GLS & CBL & I-M3 & M3s & IOB & $\mathrm{BB}$ & OD & Crest \\
\hline 1 & med. Myotis & L dentary & 10.5 & & & & & & & & \\
\hline 1 & med. Myotis & $\mathrm{R}$ dentary & 10.3 & & & & & & & & \\
\hline 2 & med. Myotis & L dentary & 10.2 & & & & & & & & \\
\hline 2 & med. Myotis & L dentary & 10 & & & & & & & & \\
\hline 2 & med. Myotis & L maxilla & & & & 6.7 & & & & & \\
\hline 2 & med. Myotis & L maxilla & & & & 6.2 & & & & & \\
\hline 2 & med. Myotis & $\mathrm{R}$ dentary & 10.3 & & & & & & & & \\
\hline 2 & Myotis leibii & L dentary & 9.8 & & & & & & & & \\
\hline 2 & Myotis sp. & L dentary & $\mathrm{n} / \mathrm{m}$ & & & & & & & & \\
\hline 2 & Myotis sp. & L dentary & $\mathrm{n} / \mathrm{m}$ & & & & & & & & \\
\hline 3 & med. Myotis & L dentary & 10.3 & & & & & & & & \\
\hline 3 & med. Myotis & L dentary & 10.1 & & & & & & & & \\
\hline 3 & med. Myotis & L dentary & 10.1 & & & & & & & & \\
\hline 3 & med. Myotis & L maxilla & & & & $\mathrm{n} / \mathrm{m}$ & & & & & \\
\hline 3 & med. Myotis & $\mathrm{R}$ dentary & 10.5 & & & & & & & & \\
\hline 3 & med. Myotis & $\mathrm{R}$ dentary & 10.1 & & & & & & & & \\
\hline 3 & med. Myotis & $\mathrm{R}$ dentary & 10 & & & & & & & & \\
\hline 3 & med. Myotis & rostrum & & & & $\mathrm{n} / \mathrm{m}$ & & 4 & & & \\
\hline 4 & Eptesicus fuscus & L dentary & $\mathrm{n} / \mathrm{m}$ & & & & & & & & \\
\hline 4 & med. Myotis & L dentary & 10.4 & & & & & & & & \\
\hline 4 & med. Myotis & L dentary & 10.4 & & & & & & & & \\
\hline 4 & med. Myotis & L dentary & 10.5 & & & & & & & & \\
\hline 4 & med. Myotis & rostrum & & & & 6.6 & 6.4 & & & & \\
\hline 4 & Myotis leibii & $\mathrm{R}$ dentary & 9.3 & & & & & & & & \\
\hline 4 & Myotis sp. & L dentary & $\mathrm{n} / \mathrm{m}$ & & & & & & & & \\
\hline 5 & Corynorhinus sp. & Cranium & & 16.1 & 15.1 & 6.2 & 6.2 & 3.9 & 9 & 6.2 & \\
\hline 5 & med. Myotis & L dentary & 10.2 & & & & & & & & \\
\hline 5 & med. Myotis & L dentary & 10.2 & & & & & & & & \\
\hline 5 & med. Myotis & L dentary & 10.3 & & & & & & & & \\
\hline 5 & med. Myotis & L dentary & 10.4 & & & & & & & & \\
\hline 5 & med. Myotis & L dentary & 10.1 & & & & & & & & \\
\hline 5 & med. Myotis & L maxilla & & & & 6.7 & & & & & \\
\hline 5 & med. Myotis & partial rostrum & & & 6.2 & & & & & & \\
\hline 5 & med. Myotis & R dentary & 10.4 & & & & & & & & \\
\hline 5 & med. Myotis & $\mathrm{R}$ dentary & 10.4 & & & & & & & & \\
\hline 5 & Myotis cf. lucifugus & cranium & & 14.4 & 14.1 & 6.6 & 5.7 & $\mathrm{n} / \mathrm{m}$ & 7.1 & 4.9 & no \\
\hline 5 & Myotis sp. & L dentary & $\mathrm{n} / \mathrm{m}$ & & & & & & & & \\
\hline 6 & med. Myotis & L dentary & 10 & & & & & & & & \\
\hline 6 & med. Myotis & L dentary & 10.1 & & & & & & & & \\
\hline 6 & med. Myotis & L dentary & 10.1 & & & & & & & & \\
\hline 6 & med. Myotis & L dentary & 10.1 & & & & & & & & \\
\hline 6 & med. Myotis & L dentary & 10.2 & & & & & & & & \\
\hline 6 & med. Myotis & L dentary & 10.3 & & & & & & & & \\
\hline 6 & med. Myotis & L dentary & 10.4 & & & & & & & & \\
\hline 6 & med. Myotis & L dentary & 10.5 & & & & & & & & \\
\hline 6 & med. Myotis & L dentary & 10.7 & & & & & & & & \\
\hline 6 & med. Myotis & $\mathrm{R}$ dentary & 10.1 & & & & & & & & \\
\hline 6 & med. Myotis & $\mathrm{R}$ dentary & 10.2 & & & & & & & & \\
\hline
\end{tabular}


Supplemental Material

M. Colburn, R. Toomey, C. Widga, and R. Olson - Holocene palentology of Bat Cave, Edmonson County, Kentucky. Journal of Cave and Karst

Studies, v.77, no.2, p.91-98.

Table S1. Continued.

\begin{tabular}{|c|c|c|c|c|c|c|c|c|c|c|c|}
\hline & & Skull element & & & & & & & & & \\
\hline Level & Taxon & & TL & GLS & CBL & I-M3 & M3s & IOB & $\mathrm{BB}$ & OD & Crest \\
\hline 6 & med. Myotis & R dentary & 10.2 & & & & & & & & \\
\hline 6 & med. Myotis & $\mathrm{R}$ dentary & 10.2 & & & & & & & & \\
\hline 6 & med. Myotis & $\mathrm{R}$ dentary & 10.2 & & & & & & & & \\
\hline 6 & med. Myotis & $\mathrm{R}$ dentary & 10.4 & & & & & & & & \\
\hline 6 & med. Myotis & $\mathrm{R}$ dentary & 10.7 & & & & & & & & \\
\hline 6 & Myotis cf. sodalis & cranium & & & & 6.7 & 5.8 & 4.1 & & & yes \\
\hline 6 & Myotis lucifugus & cranium & & 15.1 & & 6.8 & 6 & 4.1 & & & no, wide \\
\hline 6 & Myotis sodalis & cranium & & 14.2 & & 6.4 & 5.8 & 3.9 & & & yes \\
\hline 6 & Myotis sodalis & cranium & & 14 & & 6.2 & 5.8 & 3.8 & 7 & & yes \\
\hline 6 & Myotis sp. & maxilla & & & & 6.8 & 5.9 & 4.1 & & & \\
\hline 7 & med. Myotis & L dentary & 10.1 & & & & & & & & \\
\hline 7 & med. Myotis & L dentary & 10.1 & & & & & & & & \\
\hline 7 & med. Myotis & L dentary & 10.2 & & & & & & & & \\
\hline 7 & med. Myotis & L dentary & 10.3 & & & & & & & & \\
\hline 7 & med. Myotis & L dentary & 10.4 & & & & & & & & \\
\hline 7 & med. Myotis & $\mathrm{R}$ dentary & 10.4 & & & & & & & & \\
\hline 7 & med. Myotis & $\mathrm{R}$ dentary & 10.5 & & & & & & & & \\
\hline 7 & med. Myotis & $\mathrm{R}$ dentary & 10.7 & & & & & & & & \\
\hline 7 & med. Myotis & $\mathrm{R}$ maxilla & & & & $\mathrm{n} / \mathrm{m}$ & & & & & \\
\hline 7 & Myotis cf. sodalis & partial cranium & & & & $\mathrm{n} / \mathrm{m}$ & $\mathrm{n} / \mathrm{m}$ & & & & yes \\
\hline 7 & Myotis sp. & L dentary & $\mathrm{n} / \mathrm{m}$ & & & & & & & & \\
\hline 7 & Myotis sp. & $\mathrm{R}$ dentary & $\mathrm{n} / \mathrm{m}$ & & & & & & & & \\
\hline 8 & med. Myotis & L dentary & 10.2 & & & & & & & & \\
\hline 8 & med. Myotis & L dentary & 10.2 & & & & & & & & \\
\hline 8 & med. Myotis & L dentary & 10.3 & & & & & & & & \\
\hline 8 & med. Myotis & L dentary & 10.4 & & & & & & & & \\
\hline 8 & med. Myotis & L dentary & 10 & & & & & & & & \\
\hline 8 & Myotis leibii & $\mathrm{R}$ dentary & 9 & & & & & & & & \\
\hline 8 & Myotis leibii & $\mathrm{R}$ dentary & 9.1 & & & & & & & & \\
\hline 8 & Myotis sp. & R dentary & $\mathrm{n} / \mathrm{m}$ & & & & & & & & \\
\hline 9 & Eptesicus fuscus & L dentary & $\mathrm{n} / \mathrm{m}$ & & & & & & & & \\
\hline 9 & med. Myotis & L dentary & 10.2 & & & & & & & & \\
\hline 9 & med. Myotis & L dentary & 10.3 & & & & & & & & \\
\hline 9 & med. Myotis & L dentary & 10 & & & & & & & & \\
\hline 9 & med. Myotis & $\mathrm{R}$ dentary & 10.1 & & & & & & & & \\
\hline 9 & med. Myotis & $\mathrm{R}$ dentary & 10.2 & & & & & & & & \\
\hline 9 & med. Myotis & $\mathrm{R}$ dentary & 10.3 & & & & & & & & \\
\hline 9 & med. Myotis & $\mathrm{R}$ dentary & 10 & & & & & & & & \\
\hline 10 & Eptesicus fuscus & R up C1 & & & & & & & & & \\
\hline 10 & med. Myotis & L dentary & 10.1 & & & & & & & & \\
\hline 10 & med. Myotis & L dentary & 10.2 & & & & & & & & \\
\hline 10 & med. Myotis & L dentary & 10.3 & & & & & & & & \\
\hline 10 & med. Myotis & L dentary & 10.3 & & & & & & & & \\
\hline 10 & med. Myotis & L dentary & 10.4 & & & & & & & & \\
\hline 10 & med. Myotis & L maxilla & & & & 6.5 & & & & & \\
\hline 10 & med. Myotis & maxilla & & & & 6.6 & & & & & \\
\hline 10 & med. Myotis & maxilla & & & & 6.5 & 5.5 & & & & \\
\hline 10 & med. Myotis & R dentary & 10.1 & & & & & & & & \\
\hline 10 & med. Myotis & $\mathrm{R}$ dentary & 10.1 & & & & & & & & \\
\hline 10 & med. Myotis & $\mathrm{R}$ dentary & 10.3 & & & & & & & & \\
\hline
\end{tabular}


Supplemental Material

M. Colburn, R. Toomey, C. Widga, and R. Olson - Holocene palentology of Bat Cave, Edmonson County, Kentucky. Journal of Cave and Karst Studies, v.77, no.2, p.91-98.

Table S1. Continued.

\begin{tabular}{|c|c|c|c|c|c|c|c|c|c|c|c|}
\hline & & Skull element & & & & & & & & & \\
\hline Level & Taxon & & TL & GLS & CBL & I-M3 & M3s & IOB & $\mathrm{BB}$ & OD & Crest \\
\hline 10 & med. Myotis & R dentary & 10.6 & & & & & & & & \\
\hline 10 & Myotis leibii & L dentary & 9.8 & & & & & & & & \\
\hline 10 & Myotis leibii & R dentary & 9.9 & & & & & & & & \\
\hline 10 & Myotis sp. & L dentary & $\mathrm{n} / \mathrm{m}$ & & & & & & & & \\
\hline 10 & Myotis sp. & L dentary & $\mathrm{n} / \mathrm{m}$ & & & & & & & & \\
\hline 10 & Myotis sp. & L dentary & $\mathrm{n} / \mathrm{m}$ & & & & & & & & \\
\hline 10 & Myotis sp. & L dentary & $\mathrm{n} / \mathrm{m}$ & & & & & & & & \\
\hline 10 & Myotis sp. & L dentary & $\mathrm{n} / \mathrm{m}$ & & & & & & & & \\
\hline 10 & Myotis sp. & L dentary & $\mathrm{n} / \mathrm{m}$ & & & & & & & & \\
\hline 10 & Myotis sp. & L dentary & $\mathrm{n} / \mathrm{m}$ & & & & & & & & \\
\hline 10 & Myotis sp. & L dentary & $\mathrm{n} / \mathrm{m}$ & & & & & & & & \\
\hline 10 & Myotis sp. & L dentary & $\mathrm{n} / \mathrm{m}$ & & & & & & & & \\
\hline 10 & Myotis sp. & L maxilla & & & & $\mathrm{n} / \mathrm{m}$ & & & & & \\
\hline 10 & Myotis sp. & $\mathrm{R}$ dentary & $\mathrm{n} / \mathrm{m}$ & & & & & & & & \\
\hline 10 & Myotis sp. & $\mathrm{R}$ dentary & $\mathrm{n} / \mathrm{m}$ & & & & & & & & \\
\hline 10 & Myotis sp. & R dentary & $\mathrm{n} / \mathrm{m}$ & & & & & & & & \\
\hline 10 & Myotis sp. & R dentary & $\mathrm{n} / \mathrm{m}$ & & & & & & & & \\
\hline 11 & med. Myotis & L dentary & 10.2 & & & & & & & & \\
\hline 11 & med. Myotis & L dentary & 10.4 & & & & & & & & \\
\hline 11 & med. Myotis & L dentary & 10.2 & & & & & & & & \\
\hline 11 & med. Myotis & L dentary & 10.3 & & & & & & & & \\
\hline 11 & med. Myotis & L dentary & 10.6 & & & & & & & & \\
\hline 11 & med. Myotis & L dentary & 10 & & & & & & & & \\
\hline 11 & med. Myotis & L dentary & 10 & & & & & & & & \\
\hline 11 & med. Myotis & L dentary & 10 & & & & & & & & \\
\hline 11 & med. Myotis & L maxilla & & & & $\mathrm{n} / \mathrm{m}$ & & & & & \\
\hline 11 & med. Myotis & L maxilla & & & & $\mathrm{n} / \mathrm{m}$ & & & & & \\
\hline 11 & med. Myotis & L maxilla & & & & $\mathrm{n} / \mathrm{m}$ & & & & & \\
\hline 11 & med. Myotis & L maxilla & & & & $\mathrm{n} / \mathrm{m}$ & & & & & \\
\hline 11 & med. Myotis & $\mathrm{R}$ dentary & 10.3 & & & & & & & & \\
\hline 11 & med. Myotis & $\mathrm{R}$ dentary & 10.3 & & & & & & & & \\
\hline 11 & med. Myotis & $\mathrm{R}$ dentary & 10 & & & & & & & & \\
\hline 11 & med. Myotis & R dentary & 10.2 & & & & & & & & \\
\hline 11 & med. Myotis & R dentary & 10.2 & & & & & & & & \\
\hline 11 & med. Myotis & $\mathrm{R}$ maxilla & & & & 6.2 & & & & & \\
\hline 11 & med. Myotis & $\mathrm{R}$ maxilla & & & & $\mathrm{n} / \mathrm{m}$ & & & & & \\
\hline 11 & med. Myotis & rostrum & & & & 6.6 & 5.9 & & & & \\
\hline 11 & med. Myotis & rostrum & & & & 6.6 & 5.8 & & & & \\
\hline 11 & Myotis sp. & L dentary & $\mathrm{n} / \mathrm{m}$ & & & & & & & & \\
\hline 11 & Myotis sp. & $\mathrm{R}$ dentary & $\mathrm{n} / \mathrm{m}$ & & & & & & & & \\
\hline 11 & Myotis sp. & R dentary & $\mathrm{n} / \mathrm{m}$ & & & & & & & & \\
\hline 11 & Myotis sp. & $\mathrm{R}$ dentary & $\mathrm{n} / \mathrm{m}$ & & & & & & & & \\
\hline 11 & Myotis sp. & $\mathrm{R}$ dentary & $\mathrm{n} / \mathrm{m}$ & & & & & & & & \\
\hline
\end{tabular}

